\title{
Mesenchymal chondrosarcoma: Prognostic factors and outcome in 113 patients. A European Musculoskeletal Oncology Society study
}

Anna Maria Frezza ${ }^{\mathrm{a}, \mathrm{b}}$, Marilena Cesari ${ }^{\mathrm{c}}$, Daniel Baumhoer ${ }^{\mathrm{d}}$, David Biau ${ }^{\mathrm{e}}$, Stephen Bielack ${ }^{\mathrm{f}}$, Domenico Andrea Campanacci ${ }^{\mathrm{g}}$, José Casanova ${ }^{\mathrm{h}}$, Claire Esler $^{\mathrm{i}}$, Stefano Ferrari ${ }^{\mathrm{c}}$, Philipp T. Funovics ${ }^{\mathrm{j}}$, Craig Gerrand ${ }^{\mathrm{k}}$, Robert Grimer ${ }^{1}$, Alessandro Gronchi ${ }^{\mathrm{m}}$, Nicolas Haffner ${ }^{\mathrm{n}}$, Stefanie Hecker-Nolting ${ }^{\mathrm{f}}$, Sylvia Höller ${ }^{\mathrm{d}}$, Lee Jeys ${ }^{1}$, Paul Jutte ${ }^{\circ}$, Andreas Leithner ${ }^{p}$, Mikel San-Julian ${ }^{\mathrm{q}}$, Joachim Thorkildsen ${ }^{\mathrm{r}}$, Bruno Vincenzi ${ }^{\mathrm{b}}$, Reinhard Windhager ${ }^{\mathrm{j}}$, Jeremy Whelan ${ }^{\mathrm{a}, *}$

\footnotetext{
${ }^{a}$ The London Sarcoma Service, University College of London Hospital, London, United Kingdom

${ }^{\mathrm{b}}$ University Campus Bio-Medico, Rome, Italy

${ }^{\mathrm{c}}$ Istituto Ortopedico Rizzoli di Bologna, Bologna, Italy

${ }^{\mathrm{d}}$ Bone Tumor Reference Centre at the Institute of Pathology, University Hospital Basel, Basel, Switzerland

${ }^{\mathrm{e}}$ Hospital Cochin, Paris, France

${ }^{\mathrm{f}}$ The Cooperative German-Austrian-Swiss Osteosarcoma Study Group (COSS Group), Germany

${ }^{\mathrm{g}}$ Azienda Ospedaliera Universitaria Careggi, Firenze, Italy

${ }^{\mathrm{h}}$ Coimbra University Medical Center, Coimbra, Portugal

${ }^{\mathrm{i}}$ Leicester Royal Infirmary, Leicester, United Kingdom

${ }^{\mathrm{j}}$ Universitätsklinik für Orthopädie der Medizinischen, Universität Wien, Wien, Austria

${ }^{\mathrm{k}}$ Freeman Hospital, Newcastle, United Kingdom

${ }^{1}$ The Royal Orthopaedic Hospital, Birmingham, United Kingdom

${ }^{\mathrm{m}}$ Istituto Nazionale Tumori, Milano, Italy

${ }^{\mathrm{n}}$ Orthopaedic Hospital Gersthof, Wien, Austria

${ }^{\circ}$ University Medical Center Groningen, Groningen, The Netherlands

${ }^{\mathrm{p}}$ Medical University of Graz, Graz, Austria

${ }^{\mathrm{q}}$ University of Navarra, Pamplona, Spain

${ }^{\mathrm{r}}$ Norwegian Radium Hospital, Oslo, Norway
}

Received 10 September 2014; received in revised form 3 November 2014; accepted 11 November 2014 Available online 16 December 2014

\footnotetext{
* Corresponding author at: The London Sarcoma Service, University College Hospital, 1st Floor Central, 250 Euston Road, London NW1 2PG, United Kingdom. Tel.: +44 203447 9346; fax: +44 2034479055.

E-mail address: jeremy.whelan@uclh.nhs.uk (J. Whelan).
} 


\section{KEYWORDS}

Mesenchymal chondrosarcoma Chemotherapy Outcome
Abstract Background: Mesenchymal chondrosarcoma (MCS) is a distinct, very rare sarcoma with little evidence supporting treatment recommendations.

Patients and methods: Specialist centres collaborated to report prognostic factors and outcome for 113 patients.

Results: Median age was 30 years (range: 11-80), male/female ratio 1.1. Primary sites were extremities (40\%), trunk (47\%) and head and neck (13\%), 41 arising primarily in soft tissue. Seventeen patients had metastases at diagnosis. Mean follow-up was 14.9 years (range: 1-34), median overall survival (OS) 17 years (95\% confidence interval (CI): 10.3-28.6). Ninety-five of 96 patients with localised disease underwent surgery, 54 additionally received combination chemotherapy. Sixty-five of 95 patients are alive and 45 progression-free ( 5 local recurrence, 34 distant metastases, 11 combined). Median progression-free survival (PFS) and OS were 7 (95\% CI: 3.03-10.96) and 20 (95\% CI: 12.63-27.36) years respectively. Chemotherapy administration in patients with localised disease was associated with reduced risk of recurrence $(P=0.046$; hazard ratio $(\mathrm{HR})=0.48295 \% \mathrm{CI}: 0.213-0.996)$ and death $(P=0.004$; $\mathrm{HR}=0.44595 \% \mathrm{CI}: 0.256-0.774)$. Clear resection margins predicted less frequent local recurrence $(2 \%$ versus $27 \% ; P=0.002)$. Primary site and origin did not influence survival. The absence of metastases at diagnosis was associated with a significantly better outcome $(P<0.0001)$. Data on radiotherapy indications, dose and fractionation were insufficiently complete, to allow comment of its impact on outcomes. Median OS for patients with metastases at presentation was 3 years (95\% CI: $0-4.25)$.

Conclusions: Prognosis in MCS varies considerably. Metastatic disease at diagnosis has the strongest impact on survival. Complete resection and adjuvant chemotherapy should be considered as standard of care for localised disease.

(c) 2014 Elsevier Ltd. All rights reserved.

\section{Introduction}

Mesenchymal chondrosarcoma (MCS) accounts for $3-10 \%$ of all chondrosarcoma diagnoses and has distinctive clinical features [1,2]. Morphologically, MCS is characterised by a biphasic pattern of undifferentiated small blue round cells and islands of hyaline cartilage. The small cell component shows positive staining for SOX9 and negativity for FLI-1, which often helps in differential diagnosis from Ewing sarcoma [3]. Recently, the HEY1-NCOA2 fusion has been described in MCS, a marker of diagnostic utility [4].

Axial skeleton and femur are the most common primary sites for skeletal MCS; soft tissue MCS may affect meninges and have visceral involvement $[1,2,5,6]$. Clinical findings at diagnosis are usually swelling and pain. Imaging features for MCS are more aggressive than those of conventional chondrosarcoma: lesions show lytic and destructive appearances, periosteal reaction is poorly defined, cortical breakthrough and extra-osseous extension are common. Mottled calcification is present in one-third of cases, sometimes extensive. Pathological fracture is rare [7]. Few cases of MCS have been reported to be positive using fluorodeoxyglucose-positron emission tomography (FDG-PET) $[8,9]$.

MCS shows a strong tendency towards late local and metastatic recurrences. Despite a potentially prolonged clinical course, the outcome for these patients ultimately appears to be poor, with reported 10 -year survival rate in the range of $27-67 \%[1,9]$.
Less than 600 cases of MCS have been published, mainly as case reports or small case series, and we found only three studies which include more than 20 patients with follow-up data $[1,2,10,11]$.

Given the rarity of MCS and the limitations of the published reports, little evidence supports current treatment recommendations. In particular the value of radiotherapy and chemotherapy is poorly defined. The European Musculoskeletal Oncology Society (EMSOS) has previously successfully drawn together the collective experience of its members to illuminate uncommon areas of practice [12-15]. We therefore used this resource to investigate MCS, with the aim of describing current practice and identifying predictive factors to provide direction for potential prospective studies.

\section{Patients and methods}

\subsection{Data collection}

EMSOS members were invited to contribute cases to a review of patients diagnosed with MCS. The protocol synopsis and database were available on the EMSOS website. Anonymised data for patient demographics, tumour, treatment, clinical course and outcomes were obtained. Because of the rarity of this condition we accepted that some of the patients in this study will have been included in previous analyses, but all follow-up data were updated $[9,11]$. Because all participating centres were reference centres for 
musculoskeletal oncology, radiology and histology of the retrieved cases was not reviewed.

\subsection{Statistical analysis}

Descriptive analysis was made using median values and 95\% confidence interval (CI). Differences between groups were assessed using the Chi-squared test. The Cox proportional hazards model was used to assess the effect on survival outcomes of origin (skeletal/extraskeletal), primary site (axial/extremity), margins (R0/ R1) and use of chemotherapy. Multivariate analysis was performed using Cox's proportional hazard method with the inclusion of all the variables taken into account for univariate analysis (origin, primary site, margins and use of chemotherapy). Progression free survival (PFS) in patients with localised disease was calculated as the period from surgery to the first observation of disease recurrence. Overall survival (OS) was calculated from diagnosis to death or the last documented time the patient was known to be alive. Patients with no evidence of progression were censored at the last assessment. Death was considered an event regardless of the cause. Patients alive were censored at the last contact. Survival analysis was done using Kaplan-Meier (KM) survivorship. Significance was set at $P<0.05$ for two-sided tests. SPSS software was used for statistical analysis.

\section{Results}

\subsection{Patients population}

Seventeen centres and one cooperative group contributed to this study, with 128 cases collected from 1971 to 2012. Fifteen patients had no staging details and/or follow-up data, resulting in 113 patients available. Mean follow-up was 14.9 years (range: 1-34). Male/female ratio was 1.1:1 (60 males, 53 females). Median age at diagnosis was 30 years (range: $11-80$ ). Sixty-one patients $(61 / 113 ; 54 \%)$ were in the 2 nd-3rd decade of life, $34 / 113$ $(30 \%)$ in the 4 th -5 th, $18 / 113(16 \%)$ in the 6 th- 8 th. Seventy-two $(72 / 113 ; 64 \%)$ tumours had a skeletal origin, $41 / 113(36 \%)$ arose from somatic soft tissue.

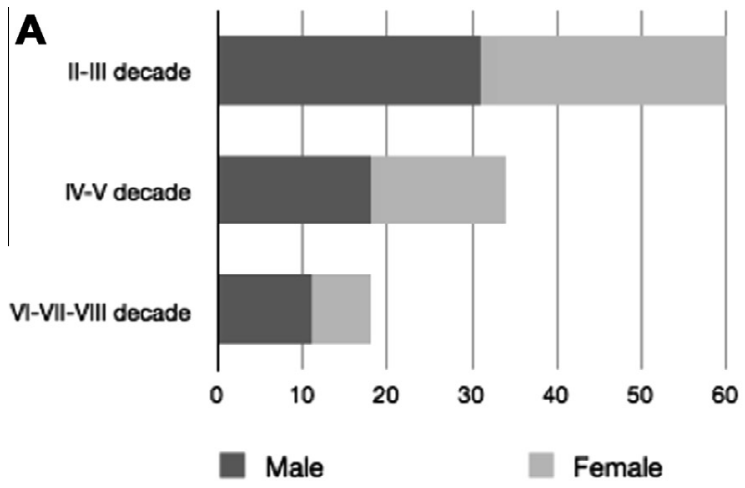

Craniofacial bones were affected in $15 / 113$ patients (13\%), trunk in 53/113 (47\%), limbs in 45/113 (40\%). Distribution by age and gender (Fig. 1A), origin and primary site (Fig. 1B) are shown. Ninety-six (96/113; 85\%) patients had localised disease at presentation.

\subsection{Treatment}

\subsubsection{Localised disease at presentation}

Ninety-five of 96 patients with localised disease underwent surgery. Resection margins were available in 76/95 (80\%): 46/76 patients $(61 \%)$ had resections with clear margins $(\geqslant 1 \mathrm{~mm}, \mathrm{R} 0)$, in $30 / 76$ patients $(39 \%)$ margins were close or involved $(<1 \mathrm{~mm}, \mathrm{R} 1)$.

Forty $(42 \%)$ patients received radiotherapy (1 definitive, 38 postoperative (PORT), 1 both pre- and postoperative). Chemotherapy was administered in 54/95 $(57 \%)$ patients with resected localised disease: $21 / 54$ $(39 \%)$ received chemotherapy preoperatively, 30/54 $(56 \%)$ postoperatively, $3 / 54(5 \%)$ both. $52 / 54$ patients $(96 \%)$ received an anthracycline, 38/54 (70\%) also received alkylating agents.

\subsubsection{Metastatic disease at presentation}

Seventeen (15\%) patients had metastases at diagnosis: $7 / 17(42 \%)$ pulmonary metastases only, $2 / 17$ (11\%) bone metastases only and 8/17 (47\%) had multiple metastatic sites. Six $(35 \%)$ underwent anthracycline-based chemotherapy, primary resection and metastasectomy. Two $(12 \%)$ underwent primary resection, metastasectomy and PORT. Four (24\%) underwent either surgery (3) or radiotherapy (1) to the primary followed by palliative anthracycline-based chemotherapy. Five (29\%) were managed with primary resection only (2), radical radiotherapy (1), palliative anthracycline based chemotherapy (1). One patient with poor performance status did not receive any treatment.

\subsubsection{Outcome and predictive factors}

The median OS was 17 years (95\% CI: 10.3-28.6). The 5 -years and 10 years estimated survival rates were $70 \%$ and $54 \%$, respectively. The median OS in patients with localised and metastatic disease at diagnosis was 20

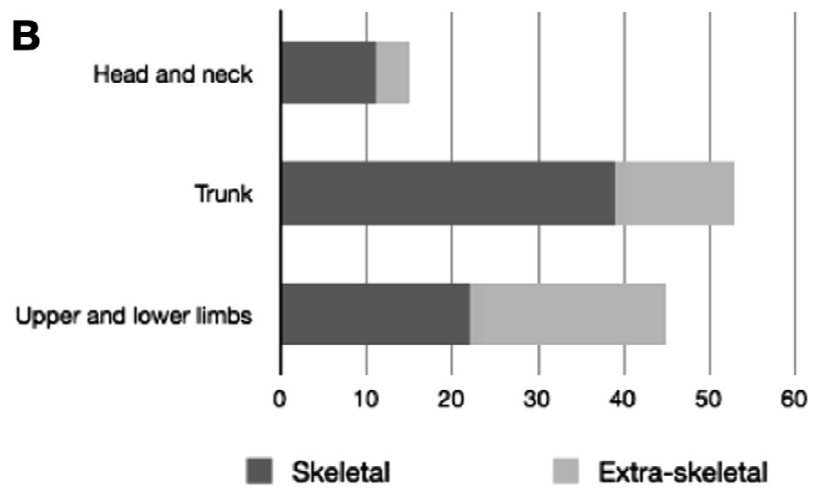

Fig. 1. Distribution by age and gender (A), origin and primary site (B). 
(95\% CI: $12.6-27.4)$ and 3 years (95\% CI: $0-4.2)$ respectively. The absence of metastases at diagnosis was associated with a significantly better outcome $(P<0.0001$; hazard ratio $(\mathrm{HR})=0.21$; 95\% CI: 0.1-0.4). KaplanMeier survival curves are shown in Fig. 2.

\subsubsection{Outcome in patients with localised disease}

Among 95 patients with resected localised disease, median PFS and OS were 7 (95\% CI: 3.0-11.0) and 20 (95\% CI: 12.6-27.4) respectively. The 5 and 10 years OS was $79 \%$ and $60 \%$, respectively. Sixteen (16/95; $17 \%$ ) patients developed local recurrence (LR), managed with surgery alone in four cases, surgery and PORT in 4, radiotherapy and chemotherapy in 1, palliative chemotherapy in 5 and palliative radiotherapy in 2. Of these 16, 11 patients developed metastatic progression (MP). One 32-year-old patient, with an extra-skeletal MCS of the pelvis and multiple peritoneal implants achieved a prolonged disease stabilisation with trabectedin (12 cycles) after progression on epirubicin and ifosfamide. Among those developing isolated LR $(5 / 16 ; 31 \%)$ only one patient died (managed with palliative chemotherapy due to surgery refusal) while 4 are alive with no evidence of disease. Thirty-four patients (36\%) developed MP without LR. Among all 45 who developed MP, 28 patients progressed in lung $(16 / 45 ; 36 \%)$ or in bone $(12 / 45 ; 26 \%)$ only, $17 / 45(38 \%)$ in multiple sites. Also, $25 / 45(55 \%)$ recurred within the first 2 years from the surgery, $8 / 45(18 \%)$ in the 3 rd-4th year, $12 / 45(27 \%)$ at the 5 th year or after. Six $(13 \%)$ patients developed MP after 10 years, and one patient progressed with lung and bone metastases 20 years after surgery and adjuvant chemotherapy.

Tissue of origin $(P=0.811)$, primary site (head and neck $P=0.968$; limbs $P=0.778$ ) and resection margins $(P=0.442)$ were not found to influence the risk of death in univariate analysis (see Table 1). However, patients who underwent R1 resection showed a significantly higher risk of LR $(1 / 46,2 \%$ versus $8 / 30,27 \%$; $P=0.002)$. Chemotherapy administration was associated with a reduced risk of recurrence $(P=0.046$; $\mathrm{HR}=0.482 \quad 95 \% \quad \mathrm{CI}: \quad 0.213-0.996)$ and death $(P=0.004$; HR $=0.445$ 95\% CI: 0.256-0.774). Median OS was not reached in the chemotherapy group and was 9 years (95\% CI: 3.527-14.473) in the surveillance group, PFS was 20 years (95\% CI: 1.769-38.231) and 4 years (95\% CI: $2.070-5.930)$ respectively. The 5-year and 10 -year OS were $84 \%$ and $80 \%$ respectively in the chemotherapy group, $73 \%$ and $46 \%$ in the surveillance group. The 5-year and 10-years PFS were 70\%, 67\% and $35 \%, 27 \%$, respectively (Fig. 3). The multivariate final model (Table 2) selected chemotherapy administration as the only variable predictive of death $(P=0.004$; $\mathrm{HR}=0.461$ 95\% CI: 0.328-0.856).

The only patient with localised unresectable disease at diagnosis was managed with chemotherapy and radiotherapy, progressed in lungs after 11 months and died from disease.

\subsubsection{Outcome in metastatic patients}

Only two patients $(2 / 17,12 \%)$ with metastases at presentation are currently alive. Five of six patients treated

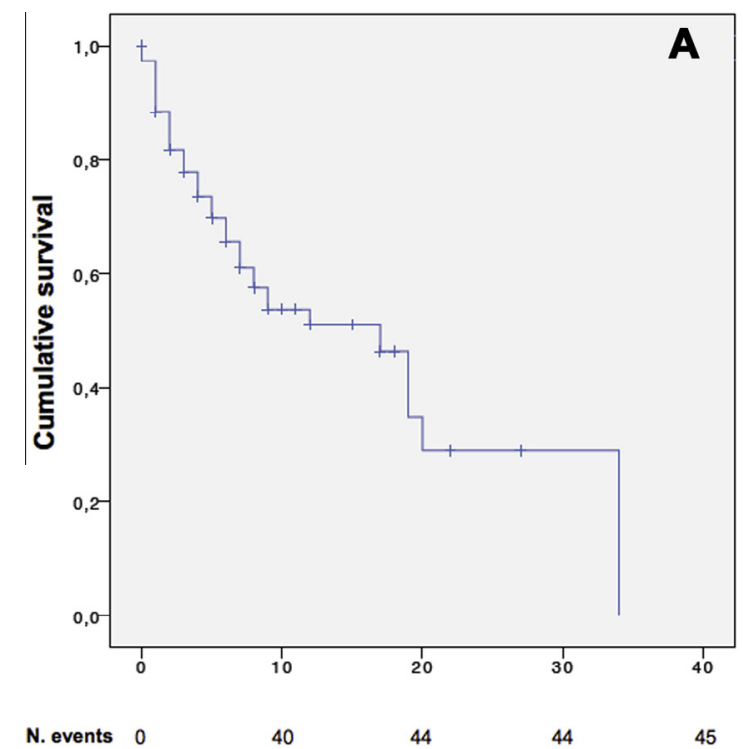

N. events 0
40

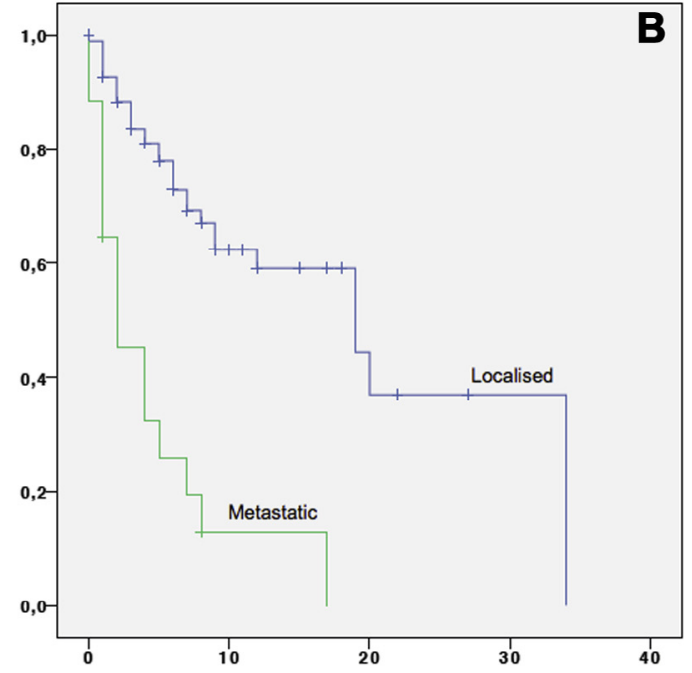

N. events

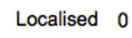

Metastatic 0

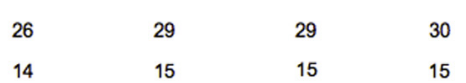

Overall survival (years)

Overall survival (years)

Fig. 2. Kaplan-Meier survival curve for the overall survival of all patients with evaluable data $(n=113)$ and comparing those with metastases $(n=17)$ and without metastases $(n=96)$ at diagnosis $(P<0.0001)$. 
Table 1

Univariate risk factors affecting survival in mesenchymal chondrosarcoma (MCS) patients with localised at diagnosis $(n=95)$.

\begin{tabular}{llll}
\hline Factors & Number evaluable $(\%)$ & Hazard-ratio $(95 \%$ confidence interval) & $P$-value \\
\hline Tissue of origin & 95 & $1.066(0.630-1.805)$ & 0.811 \\
- Skeletal & $61(64 \%)$ & 1 & \\
- Extra-skeletal & $34(36 \%)$ & $1.015(0.505-2.038)$ \\
Primary sites & 95 & 1 & 0.968 \\
- Head and neck & $15(16 \%)$ & $1.102(0.561-2.168)$ \\
- Trunk & $43(45 \%)$ & & $0.798(0.438-1.455)$ \\
- Limbs & $37(39 \%)$ & 1 & 0.778 \\
Resection margins & 76 & & \\
- R0 & $46(61 \%)$ & $0.445(0.256-0.774)$ \\
- R1 & $30(39 \%)$ & 1 \\
Chemotherapy & 95 & \\
- Yes & $54(57 \%)$ & $41(43 \%)$ & 0.004 \\
- No & &
\end{tabular}

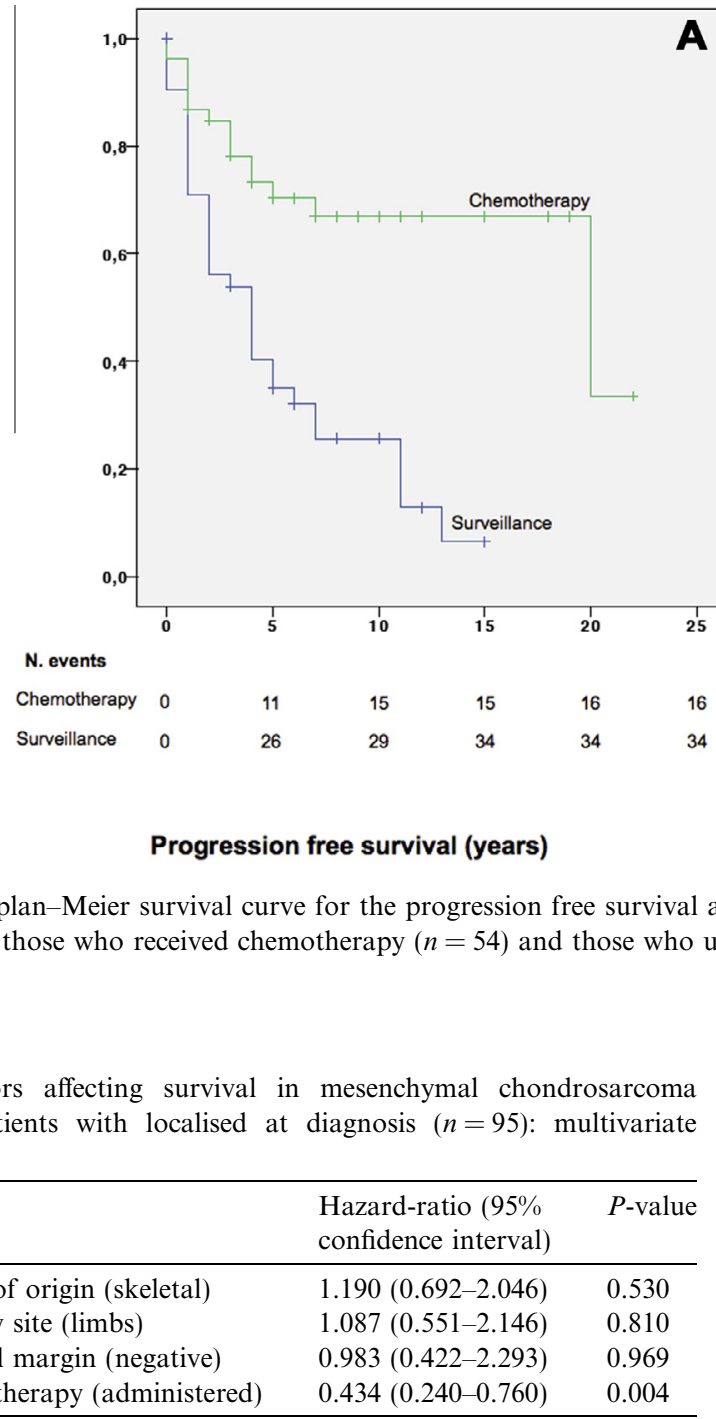

Table 2

Risk factors affecting survival in mesenchymal chondrosarcoma (MCS) patients with localised at diagnosis $(n=95)$ : multivariate model.

\begin{tabular}{llc}
\hline Factors & $\begin{array}{l}\text { Hazard-ratio }(95 \% \\
\text { confidence interval) }\end{array}$ & $P$-value \\
\hline - Tissue of origin (skeletal) & $1.190(0.692-2.046)$ & 0.530 \\
- Primary site (limbs) & $1.087(0.551-2.146)$ & 0.810 \\
- Surgical margin (negative) & $0.983(0.422-2.293)$ & 0.969 \\
- Chemotherapy (administered) & $0.434(0.240-0.760)$ & 0.004 \\
\hline
\end{tabular}

with chemotherapy, primary resection and metastasectomy ultimately died of disease. A 52 year-old patient with extra-skeletal MCS of the thigh and an isolated spinal metastasis underwent five cycles of epirubicin and ifosfamide followed by surgery for both sites and is currently alive and progression free after 1 year. A 14 year-old patient with a skeletal pelvic MCS metastatic at diagnosis to lungs and mediastinal lymph nodes managed with radiotherapy and chemotherapy including high-dose chemotherapy with stem cell rescue, remains progression-free after 8 years.

\section{Discussion}

This series collected from sarcoma reference centres is the largest reporting on clinical features, management and outcome for patients with MCS.

Consistent with previous studies, the peak of incidence for MCS is in the 2nd-3rd decade of life, both genders were equally affected and approximately twothirds of all cases primarily affect the skeleton, with 
Table 3

Currently available guidelines on the management of mesenchymal chondrosarcoma (MCS).

\begin{tabular}{|c|c|c|c|c|c|}
\hline Guideline & Year & $\begin{array}{l}\text { Statement on chemotherapy } \\
\text { role }\end{array}$ & $\begin{array}{l}\text { Statement on } \\
\text { systemic therapy } \\
\text { agents }\end{array}$ & Level of evidence & Grade of recommendation \\
\hline $\begin{array}{l}\text { National } \\
\text { Comprehensive } \\
\text { Cancer } \\
\text { Network } \\
\text { (NCCN) }\end{array}$ & 2014 & $\begin{array}{l}\text { Recently, Cesari and } \\
\text { colleagues reported that the } \\
\text { addition of chemotherapy } \\
\text { improved survival rate in } \\
\text { patients with MCS [11]. An- } \\
\text { other report from the Ger- } \\
\text { man study Group also } \\
\text { confirmed that outcome was } \\
\text { better in younger patients } \\
\text { with MCS who received che- } \\
\text { motherapy [9]. In absence of } \\
\text { data from randomised pro- } \\
\text { spective trials, the role of } \\
\text { chemotherapy in the treat- } \\
\text { ment of chondrosarcoma re- } \\
\text { mains undefined }\end{array}$ & $\begin{array}{l}\text { Follow Ewing's } \\
\text { sarcoma regimes }\end{array}$ & \multicolumn{2}{|c|}{$\begin{array}{l}\text { 2B (based upon lower-level evidence, there is } \mathrm{NCCN} \\
\text { consensus that the intervention is appropriate) }\end{array}$} \\
\hline $\begin{array}{l}\text { European Society } \\
\text { of Medical } \\
\text { Oncology } \\
\text { (ESMO) }\end{array}$ & 2014 & $\begin{array}{l}\text { Recent evidence suggests } \\
\text { that mesenchymal } \\
\text { chondrosarcoma may be } \\
\text { chemotherapy sensitive, and } \\
\text { may be considered for } \\
\text { adjuvant or neoadjuvant } \\
\text { therapy }[9,11]\end{array}$ & $\begin{array}{l}\text { Most authorities } \\
\text { suggest an Ewing- } \\
\text { type chemotherapy } \\
\text { regime }\end{array}$ & $\begin{array}{l}\mathrm{V} \text { (studies without } \\
\text { control group, case } \\
\text { reports, experts } \\
\text { opinions) }\end{array}$ & $\begin{array}{l}\text { B (strong or moderate evidence for } \\
\text { efficacy but with a limited clinical } \\
\text { benefit, generally recommended) }\end{array}$ \\
\hline $\begin{array}{r}\text { British Sarcoma } \\
\text { Group (BSG) }\end{array}$ & 2010 & Same as ESMO guidelines & None & Not provided & \\
\hline
\end{tabular}

trunk and limbs similarly involved $[1,2,11]$. The presence of metastases at presentation was found to strongly influence survival. Our survival rate is higher compared with that reported by Cesari et al. or Nakashima et al. (10-years OS rate $21 \%$ and $27 \%$, respectively), though similar to D'Antonello et al. $(67 \%)[2,9,11]$. This may be explained by the smaller number of patients with metastases at diagnoses included in this series $(15 \%$ and $6 \%$, respectively).

Patients with localised disease at diagnosis treated by surgery showed the most favourable outcome, with a median OS of 20 years. Interestingly, the outcome was favourable also for the small number of patients who developed isolated LR: among five patients, four treated by surgery are still alive and disease free while one, managed with palliative chemotherapy, died. Approximately half of the patients with localised disease at diagnosis developed MP, involving lungs or bone in most cases. Median time to MP has been previously reported in the range of 18-42 months, with most of the recurrences occurring within the first 5 years $[1,2,9,11]$. Despite being more common in the first 2 years after diagnosis ( $55 \%$ of cases in our series), late recurrences are not unusual $[1,2]$. In the present analysis, $27 \%$ of patients progressed after 5 years, $13 \%$ after 10 years and one patients developed lung metastases after 20 years. These results, together with those previously reported, argue for prolonged follow-up.
Currently, no reliable predictive factors are available for localised MCS. Vencio et al. reported a better survival in patients with MCS of the jaw bones compared to historical results from unselected series [16]. Conversely, Harwood et al. suggested that an axial origin rather than a peripheral limb location and pain as a presenting symptom could represent unfavourable prognostic factors [17]. Other studies proposed a negative correlation of hemangiopericytic features, proliferation rate and extra-skeletal origin with prognosis $[1,11,18]$. In our series, origin and primary site did not have any impact on outcome. No data on pathological features and symptoms have been collected.

Surgery is the mainstay of local treatment with evidence to support improved survival in patients undergoing wide surgical resection [11]. The concomitant use of radiotherapy and chemotherapy may have a role when disease is unresectable, although convincing evidence are still lacking $[2,16,19]$. In this series, all but one patient with localised disease at diagnosis underwent surgery, showing a consistency across the contributing centres. The incidence of LR was found to be significantly higher in patients undergoing surgery with positive or close margins, suggesting that clear margins remain an important goal to pursue for patients with localised disease. Data provided on radiotherapy were rather incomplete and therefore no comments can be made regarding its impact on the outcome. 
Chemotherapy administration was associated with a significant reduction in the risk of recurrence and death in patients with localised disease. Prior smaller studies had suggested a value for chemotherapy in MCS, influencing current clinical guidelines, as summarised in Table 3 $[9,11,20]$. In the retrospective study by Cesari et al., disease free survival (DFS) in patients between 5 and 10 years after surgical remission of disease was $76 \%$ with chemotherapy and $17 \%$ without $(P=0.008)$ [11]. The outcome in the series described by D'Antonello et al., including 14 young MCS patients with localised disease most of whom received chemotherapy, also compared favourably to those previously reported [9]. There is no consensus regarding the best regimen to be used in MCS, as also shown by the heterogeneity in the agents chosen within and across the different contributing centres. In our series, all but two patients treated with chemotherapy received an anthracycline and most received alkylating agents, supporting a recommendation for these agents to be used for (neo-)adjuvant chemotherapy of MCS in the future.

Due to the small number of enrolled patients, the incompleteness of the data and the lack of consistency in treatment approach, recommendations on the management of patients with metastases cannot be made. The outcome in patients with metastases at presentation remains poor and, despite prolonged survival, most will ultimately die from the disease. Similarly to previous reports, median OS in our analysis was 3 years (32.9 months in the series by Cesari et al.) and only two patients with metastases at diagnosis are still alive. An aggressive multimodal management did not seem to be curative (5/6 patients ultimately died from disease).

This study has some limitations, including its retrospective nature, the lack of centralised pathology review and the contribution of multiple centres, which restricts the amount of data collectable in order to encourage participation and accounts for incompleteness. However, we believe that our findings together with those previously reported could represent a valuable starting point to outline guidelines in this rare disease, promote a more standardised approach and encourage an international effort to include MCS patients in prospective studies, with the view to further improve outcome in these patients.

\subsection{Recommendations for practice}

The following recommendations take into account data from this and previous series and recognise that further observational studies of current practice are unlikely to provide much further insight. By suggesting a consistent approach to treatment of MCS, the possibility of future audits by EMSOS may overcome the limitations described and allow firmer statements to be made on the effectiveness of interventions. Patients with MCS should be managed in reference centres. Those with localised disease should undergo surgery to achieve clear margins and receive (neo-)adjuvant chemotherapy with doxorubicin and ifosfamide or cisplatin. Follow-up should take account of the long period during which patients are at risk of recurrence. Less information is available about the most appropriate treatment for patients with metastases at presentation and further studies are required.

\section{Conflict of interest statement}

None declared.

\section{References}

[1] Huvos AG, Rosen G, Dabska M, Marcove RC. Mesenchymal chondrosarcoma. A clinicopathologic analysis of 35 patients with emphasis on treatment. Cancer 1983;51(7):1230-7.

[2] Nakashima Y, Unni KK, Shives TC, Swee RG, Dahlin DC. Mesenchymal chondrosarcoma of bone and soft tissue. A review of 111 cases. Cancer 1986;57(12):2444-53.

[3] Fletcher CDM, Bridge JA, Hogendoorn PCW, Mertens F. World Health Organization classification of tumours of soft tissue and bone; 2013.

[4] Wang L, Motoi T, Khanin R, Olshen A, Mertens F, Bridge J, et al. Identification of a novel, recurrent HEY1-NCOA2 fusion in mesenchymal chondrosarcoma based on a genome-wide screen of exon-level expression data. Genes Chromosomes Cancer 2012;51(2):127-39.

[5] Rossetto A, Saccomano E, Zompicchiatti A, Avellini C, Toffoli S, Miolo G, et al. Mesenchymal chondrosarcoma of the spleen: report of a case. Tumori 2011;97(4):e10-5.

[6] Gomez-Brouchet A, Soulie M, Delisle MB, Escourrou G. Mesenchymal chondrosarcoma of the kidney. J Urol 2001; 166(6):2305.

[7] Douis H, Saifuddin A. The imaging of cartilaginous bone tumours. II. Chondrosarcoma. Skeletal Radiol 2013;42(5): 611-26.

[8] Lee E, Lee HY, Choe G, Kim KJ, Lee WW, Kim SE. Extraskeletal intraspinal mesenchymal chondrosarcoma; 18FFDG PET/CT finding. Clin Nucl Med 2014;39(1):e64-6.

[9] Dantonello TM, Int-Veen C, Leuschner I, Schuck A, Furtwaengler R, Claviez A, et al. Mesenchymal chondrosarcoma of soft tissues and bone in children, adolescents, and young adults: experiences of the CWS and COSS study groups. Cancer 2008;112(11):2424-31.

[10] Lightenstein L, Bernstein D. Unusual benign and malignant chondroid tumors of bone. A survey of some mesenchymal cartilage tumors and malignant chondroblastic tumors, including a few multicentric ones, as well as many atypical benign chondroblastomas and chondromyxoid fibromas. Cancer 1959; 12:1142-57.

[11] Cesari M, Bertoni F, Bacchini P, Mercuri M, Palmerini E, Ferrari S. Mesenchymal chondrosarcoma. An analysis of patients treated at a single institution. Tumori 2007;93(5):423-7.

[12] Grimer RJ, Gosheger G, Taminiau A, Biau D, Matejovsky Z, Kollender Y, et al. Dedifferentiated chondrosarcoma: prognostic factors and outcome from a European group. Eur J Cancer 2007;43(14):2060-5.

[13] Grimer RJ, Bielack S, Flege S, Cannon SR, Foleras G, Andreeff I, et al. Periosteal osteosarcoma - a European review of outcome. Eur J Cancer 2005;41(18):2806-11.

[14] Grimer RJ, Cannon SR, Taminiau AM, Bielack S, KempfBielack B, Windhager R, et al. Osteosarcoma over the age of forty. Eur J Cancer 2003;39(2):157-63. 
[15] Bielack SS, Schroeders A, Fuchs N, Bacci G, Bauer HC, Mapeli $\mathrm{S}$, et al. Malignant fibrous histiocytoma of bone: a retrospective EMSOS study of 125 cases. European Musculo-Skeletal Oncology Society. Acta Orthop Scand 1999;70(4):353-60.

[16] Vencio EF, Reeve CM, Unni KK, Nascimento AG. Mesenchymal chondrosarcoma of the jaw bones: clinicopathologic study of 19 cases. Cancer 1998;82(12):2350-5.

[17] Harwood AR, Krajbich JI, Fornasier VL. Mesenchymal chondrosarcoma: a report of 17 cases. Clin Orthop Relat Res 1981;158:144-8.
[18] Nussbeck W, Neureiter D, Soder S, Inwards C, Aigner T. Mesenchymal chondrosarcoma: an immunohistochemical study of 10 cases examining prognostic significance of proliferative activity and cellular differentiation. Pathology 2004;36(3):230-3.

[19] Salvador AH, Beabout JW, Dahlin DC. Mesenchymal chondrosarcoma - observations on 30 new cases. Cancer 1971;28(3): 605-15.

[20] Shakked RJ, Geller DS, Gorlick R, Dorfman HD. Mesenchymal chondrosarcoma: clinicopathologic study of 20 cases. Arch Pathol Lab Med 2012;136(1):61-75. 